\title{
FUNDOS DE PENSÃO COMO FINANCIADORES DA ATIVIDADE ECONÔMICA
}

\section{RESUMO}

A geração de poupança interna e a ampliação do investimento produtivo é condição para alcançar e manter taxas de crescimento econômico compatíveis com o desenvolvimento social. Os fundos de pensão, com os recursos disponíveis para investir, possibilitam alavancar o desenvolvimento de um país na medida em que canalizam esses recursos para o setor produtivo. Diante dessa perspectiva, este estudo propõe analisar o desempenho das aplicações em renda variável desses fundos, aqui considerados investimento produtivo, por meio do Capital Asset Pricing Model (CAPM) e dos índices de Sharpe e $\mathrm{M}^{2}$. Estes se prestam a avaliar o investimento realizado em relação ao risco e ao retorno da carteira. A partir da metodologia proposta, verificou-se que os investimentos em ações incorreram em retornos superiores aos esperados, garantindo eficiência na remuneração pelo risco, gerando, por um lado, maior valor agregado ao fundo e, por outro, um incremento da poupança interna do país, respaldado pela aplicação de recursos no setor produtivo.

\section{Hudson Fernandes Amaral \\ UFMG}

\author{
Caroline Sales Issa Vilaça \\ UFMG

\section{Camila Figueiredo Marques Barbosa \\ UFMG}

\author{
Valéria Gama Fully Bressan \\ UFMG
}

\begin{abstract}
The production of domestic savings and the amplification of the productive investment are the conditions to reach and to maintain rates of economical growth compatible with the social development. The pension funds, with the available resources to invest, make possible to leverage the development of a nation, as they channel these resources for the country's productive sector. At this perspective, this study intends to analyze the performance of the investments in variable income of these funds, here considered productive investments, through the Capital Asset Pricing Model (CAPM), Sharpe Index and $\mathrm{M}^{2}$ Measure. Those models are rendered to evaluate the investment accomplished - in relation to the risk and return of the portfolio. Starting from the proposed methodology, it was verified that the investments in stocks incurred in superior returns to the expected ones and obtained efficient reward-to-risk, generating, by one hand, a larger aggregated value to the fund, and by the other, an increment of the intern savings of the country - backed by the application of resources in the productive section.
\end{abstract}

PALAVRAS-CHAVE Fundos de pensão, poupança interna, investimento produtivo, carteiras de investimento, Capital Asset Pricing Model. KEY WORDS Pension funds, domestic savings, productive investment, investment portfolios, Capital Asset Pricing Model. 


\section{INTRODUÇÃO}

A geração de um volume mínimo de poupança interna de forma contínua é um dos principais fatores de sustentabilidade do crescimento de uma economia. Essa poupança viabiliza os investimentos que são canalizados ao setor produtivo por meio do sistema financeiro. Devido à magnitude das somas administradas, os investidores institucionais, agrupados em fundos mútuos de investimentos, seguradoras e entidades fechadas de previdência privada, desempenham importante papel na formação de poupança interna.

Entretanto, na prática, nem toda poupança é destinada a investimentos na formação bruta de capital fixo, e somente estes podem alavancar o processo de crescimento econômico. Diante dessa perspectiva, torna-se importante otimizar a alocação dos recursos dos fundos de pensão. Deve-se também ter em vista que o fim último desses fundos é garantir a concessão de benefícios aos seus participantes, o que implica empregar os recursos nas modalidades mais rentáveis, sempre se levando em consideração o risco.

O objetivo deste estudo é estimar os retornos dos investimentos em renda variável, considerados como investimento produtivo, e compará-los com os respectivos retornos reais dos fundos de pensão. O estudo busca responder à seguinte questão: o retorno real da carteira de ações dos fundos de pensão superou o retorno estimado no período de janeiro de 1999 a março de 2001?

A investigação foi conduzida da seguinte forma: num primeiro momento, identificou-se a composição da carteira de investimentos, medindo-se a rentabilidade mensal e o retorno médio das carteiras de ações das entidades no período total de análise considerado (abril de 1999 a março de 2001), bem como nos subperíodos propostos (abril de 1999 a março de 2000 e de abril de 2000 a março de 2001); num segundo momento, foi então calculado, por meio da aplicação do Capital Asset Pricing Model (CAPM), o retorno estimado mensal para os períodos propostos; e por fim, mensurou-se o Índice de Sharpe e o Índice de Franco Modigliani e Leah Modigliani (Índice $\mathrm{M}^{2}$ ), a fim de complementar a análise de desempenho dos fundos durante o referido período.

O artigo apresenta, primeiramente, uma revisão da literatura. Em seguida, é feita uma caracterização do Capital Asset Pricing Model (CAPM) e dos índices de Sharpe e $\mathrm{M}^{2}$, que serviram como base para descrever o comportamento dos preços dos títulos e fornecer mecanismos de avaliação do investimento realizado em relação ao risco e ao retorno de toda a carteira. Em seguida, são apresentados os dados utilizados e os resultados obtidos.

\section{FUNDOS DE PENSÃO}

Segundo Baima (1998), é de extrema importância o papel desempenhado pelos fundos de pensão, tanto do ponto de vista social, pelos benefícios que proporcionam aos seus participantes e pelo papel que desempenham na criação de empregos, quanto do ponto de vista econômico, por serem os mais importantes investidores institucionais, dispondo de recursos aplicados em longo prazo, essenciais à formação bruta de capital fixo da economia, à democratização do capital das empresas, ao desenvolvimento do programa de privatização e à geração de poupança interna.

Os fundos de pensão são os principais detentores domésticos de liquidez, com aplicações crescentes nos últimos anos. Seus investimentos passaram de 3,3\% do PIB, em 1990, para 14,5\%, em 2001, demonstrando o crescimento dos ativos disponíveis para investimento em relação ao PIB brasileiro. No entanto, os fundos de pensão no Brasil ainda não tem a relevância que têm em outros países: na Holanda o valor dos ativos dos fundos de pensão é maior do que o PIB; nos Estados Unidos, é próximo de $80 \%$ do PIB.

\section{Riscos dos fundos de pensão}

Os principais riscos incorridos pelos fundos de pensão são o atuarial e o de mercado. O equilíbrio atuarial se estende além do equilíbrio financeiro. Este requer que as despesas e demais desembolsos correntes sejam pelo menos igualados às receitas correntes, somadas às provisões ou outros tipos de reservas acumuladas. O equilíbrio atuarial pressupõe a existência de fontes que sejam capazes de se equiparar às despesas e demais desembolsos futuros incorridos. Assim, o risco atuarial está relacionado com as estimativas, inexatas, da taxa de mortalidade dos beneficiários (Pereira et al., 1997).

O risco de mercado consiste no risco de que os ativos acumulados não sejam suficientes para cobrir os desembolsos prometidos. Modernas teorias de carteira sugerem que a diversificação da carteira pode reduzir o risco que surge das diferentes performances de empresas e indústrias individuais, mas não pode reduzir o risco decorrente da má performance da economia como um todo; ou seja, o risco sistemático ou não diversificável, medido pelo coeficiente beta. O gerenciamento do risco de mercado se revela uma ação de extrema relevância na gestão dos recursos dos fundos de pensão. Tal atividade ganha ainda mais importância para os planos previdenciários de benefício definido, cujos administradores devem buscar, incessantemente, o necessário equilí- 
brio econômico-financeiro entre os ativos e o respectivo passivo atuarial (Fiabv, 2002).

As políticas de investimento dos fundos de pensão variam significativamente entre os países como reflexo de distintos contextos institucionais e regulatórios, do grau de desenvolvimento e diversificação dos mercados de capitais domésticos, de fatores macroeconômicos, tais como: taxa de inflação, nível do déficit público, tendências da taxas de juros, e também do nível de rentabilidade das empresas que buscam recursos nos mercados financeiros. Embora o que determine a estratégia de investimentos dos fundos seja a interação de todos esses elementos, os requisitos e as regras para os investimentos dos fundos, fixados pelos órgãos de supervisão, aparecem como o principal condicionante da distribuição das carteiras de ativos de fundos de pensão (Fiabv, 2002).

No Brasil, o Conselho Monetário Nacional (CMN) define os limites máximos para os investimentos nas diferentes categorias de ativos dos fundos de pensão, com o intuito de assegurar que as instituições não incorram em riscos excessivos, como a concentração de aplicações em apenas um tipo de ativo ou a aquisição de ativos de alto risco.

\section{Fundos de pensão e investimento produtivo}

Segundo Shaw e Mckinnon (1973, apud Studart, 2000), a melhor política para o incremento da poupança e investimentos é, na verdade, a falta de política. Em um mercado perfeito, a liberalização financeira seria a única política necessária e a melhor maneira para se alcançar elevados níveis de poupança e investimento. Portanto, se os fundos de pensão fossem livres para investir onde houvesse a possibilidade de retornos mais elevados, isso geraria um maior nível de poupança agregada e de investimento.

No entanto, de acordo com Studart (2000), a teoria neokeynesiana falha ao desconsiderar a importância da estrutura financeira no financiamento do processo produtivo. A experiência mostra que a liberalização financeira - que, na teoria, geraria uma intermediação financeira mais flexível e mercados mais eficientes - e as situações de altos retornos em ativos financeiros, não resultaram em elevados níveis de poupança agregada e investimento. Cintra (2000), ao analisar os processos de liberalização financeira interna e externa, entre 1974 e 1982, dos países do Cone Sul (Argentina, Chile e Uruguai), os primeiros a adotarem esse modelo, defende que taxas de juros elevadas e políticas financeiras liberalizantes não geram aumento de poupança nem tampouco de investimento. Segundo Cintra, a desregu- lamentação, ao elevar a taxa de juros, pode ampliar a "poupança financeira", ou seja, pode impedir a canalização dos recursos financeiros para o investimento produtivo, fazendo-os circular numa órbita financeira sob a forma de fundos de curto prazo e títulos da dívida pública e privada. Cintra ainda ressalta que os problemas do subdesenvolvimento decorrem da ausência de mecanismos de financiamento, bem como da dificuldade de se canalizar esses recursos para projetos de investimento.

Segundo Miranda et al. (1998), a ampliação do investimento produtivo interno é condição para alcançar e manter taxas de crescimento econômico compatíveis com o desenvolvimento social. Os fundos de pensão podem atuar como agentes do desenvolvimento econômico ao investirem seus recursos de forma produtiva, embora não exista consenso sobre o que exatamente é um investimento produtivo.

De acordo com Matijascic (1994), os fundos de pensão somente devem ser considerados investidores produtivos na medida em que seus recursos sejam destinados a investimentos que visem ao aumento da capacidade produtiva. Assim, o aumento da participação dos fundos de pensão no mercado de capitais concorreria para melhorar as condições de financiamento das empresas domésticas se esses recursos fossem direcionados para as aplicações realizadas no mercado primário.

Há uma outra linha de pensamento que defende que os fundos de pensão realizam investimentos produtivos ao terem em suas carteiras ações de empresas, sem que seja necessária a compra das ações quando da emissão primária dos títulos. Segundo Castro et al. (1994), ao comprar títulos no mercado secundário, os fundos estariam incentivando os negócios em bolsas de valores, estimulando a emissão de novas ações ou até mesmo a abertura de capital. Desta maneira, segundo a Federación Iberoamericana de Bolsas de Valores - Fiabv (2002), o elemento chave desse ciclo é a liquidez. A demanda extra por títulos, advinda de uma participação maior dos fundos de pensão, elevaria as taxas preço/lucro provocando uma redução no custo de captação de recursos por meio da emissão de ações. Nesse sentido, de acordo com o International Finance Corporation (1996, apud Fiabv, 2002), organismo financeiro de investimento vinculado ao Banco Mundial, as empresas já listadas seriam encorajadas a levantar mais recursos, enquanto outras seriam atraídas para o mercado de capitais. Este órgão destaca o aumento do número de companhias listadas como sendo um dos elementos que comprovaria o efeito dinamizador dos fundos. 
Neste estudo, toma-se como investimento produtivo os investimentos em ações. Logo, toda a carteira dos fundos de pensão investida em ações, mesmo que não tenha proporcionado o aumento da capacidade instalada, ou que não tenha tido poder de decisão nas estratégias das empresas, foi considerada investimento produtivo.

Há ainda um outro ponto que legitima a viabilidade de se assumir que os investimentos produtivos sejam aqueles em que os fundos de pensão adquirem parte de empresas, por meio de ações negociadas em bolsa ou por meio de emissão primária. Trata-se da existência de certa facilidade de acesso às informações sobre este tipo de investimento, fato que não ocorre com tanta facilidade no caso dos investimentos de fundos nas compras de ações no mercado primário.

\section{Fundos de pensão e mercado de capitais}

De acordo com Motta (2001), o mercado de capitais é um sistema fundamental para a formação e a alocação de capital de forma eficiente, e no montante adequado, para o financiamento do crescimento econômico. Um mercado de capitais forte traz benefícios diretos para a atividade econômica. Por um lado, aumenta as alternativas de investimento e reduz seu custo, e, de forma combinada, significa mais crescimento efetivo. Por outro lado, eleva a competitividade da economia como um todo.

Segundo a Fiabv (2002), um dos traços marcantes do desenvolvimento recente dos mercados financeiros nos países desenvolvidos é a importância crescente dos investidores institucionais como mobilizadores de poupança interna - notadamente, os fundos de pensão e os fundos mútuos de investimento. São as ações e os títulos negociáveis de longo prazo, transacionados no mercado de capitais, que constituem os ativos financeiros mais adequados para os que procuram investir em ativos que garantam um fluxo estável de receitas compatível com seus compromissos de geração de renda contratual. Os fundos de pensão constituem, nesse contexto, parte importante desse padrão de financiamento, na medida em que os mesmos detêm grande parcela dos investimentos diretos em bolsa.

Motta (2001) ressalta ainda que há uma correlação positiva entre um mercado de capitais forte e a solvência dos fundos de pensão. A existência de melhores alternativas de investimento permite aos administradores dos fundos previdenciários obterem maior retorno na carteira, reduzirem o risco e aumentarem a credibilidade dos fundos, resultando em melhores aposentadorias.

\section{DESEMPENHO DOS FUNDOS DE PENSÃO}

Os dois determinantes básicos do preço de um ativo são o risco e o retorno. Assim, as principais decisões financeiras devem ser vistas em termos de retorno esperado, risco esperado e seu impacto combinado ao preço do ativo.

Segundo Pereira et al. (1997), para avaliar o desempenho de um fundo de pensão é necessário avaliar sua taxa de retorno e compará-la à rentabilidade de uma carteira de referência que tenha um risco igual a seu custo de oportunidade. Os fundos podem, eventualmente, ter prejuízos, pois atuam em mercados eficientes, nos quais as informações geram reflexos rápidos sobre os preços dos títulos que, por sua vez, espelham rigorosamente toda a informação disponível. Vem daí a necessidade de se otimizar a estratégia de risco.

De acordo com Sharpe et al. (1995), o risco total de um título individual ou de uma carteira é o resultado da combinação do risco não-sistemático, ou diversificável, e do risco sistemático, parcela do risco que não pode ser eliminada pela diversificação. A teoria básica relativa a risco e retorno é normalmente estudada pelos modelos de equilíbrio (precificação) dos ativos financeiros, que explicam o comportamento dos preços dos títulos e fornecem mecanismos de avaliação do investimento proposto ou realizado sobre o risco e o retorno de toda a carteira. Vejamos os principais modelos de precificação disponíveis.

\section{Capital Asset Pricing Model}

O Capital Asset Pricing Model (CAPM) é um dos modelos de precificação de ativos mais utilizados hoje. A teoria do CAPM estipula que a taxa de rentabilidade esperada dos ativos com risco está linearmente ligada a dois fatores comuns: a taxa livre de risco e a taxa de retorno esperado da carteira de mercado. Este modelo estabelece as relações de risco e retorno esperado para verificar se um determinado título está sendo negociado dentro de seu preço justo. O prêmio pelo risco, que é igual à diferença entre o retorno esperado deste ativo e aquele do ativo livre de risco, mede a remuneração do risco que um investidor suporta quando investe uma unidade de seu capital neste ativo (Gitman, 1997).

O retorno esperado de qualquer ativo pode ser dado pela equação:

$$
R_{i}=R_{f}+\left[\beta_{i} \times\left(R_{m}-R_{f}\right)\right]
$$

Em que:

$R_{i}=$ retorno esperado do ativo ou carteira $i$;

$R_{f}=$ retorno do ativo livre de risco; 
$\beta_{\mathrm{i}}=$ coeficiente beta ou índice de risco não diversificável para o ativo $i$; e

$R_{m}=$ retorno de mercado.

Sendo o retorno exigido sobre um ativo (Ri) uma função do beta $\left(\beta_{\mathrm{i}}\right)$, que mede o risco não-diversificável: quanto maior for o risco, maior será o retorno exigido.

Neste estudo, o beta foi calculado pelo modelo de mercado, cuja metodologia consiste na utilização da regressão linear simples do excesso de retorno mensal do título (ou carteira) i sobre o excesso de retorno da carteira mercado $\left(\mathrm{R}_{\mathrm{m}}\right)$. Utiliza-se o excesso de rentabilidade dos ativos, e não a rentabilidade em si, pois o que realmente importa para o investidor é o retorno efetivo desse ativo decorrente da existência de risco.

\section{Índice de Sharpe}

Sharpe et al. (1995) denominam o índice "razão prêmio pela variabilidade". Utiliza-se como paradigma a linha de mercado de capitais, linha essa que estabelece uma relação entre retorno e risco de títulos, em que o risco é medido pelo desvio padrão, de forma a se obter a linha de fronteira eficiente, em que, dado um nível de risco, consegue-se o máximo retorno e, dado um nível de retorno, atinge-se o mínimo risco.

O índice de Sharpe é a razão entre o prêmio pelo risco da carteira e o seu desvio padrão, medindo, dessa forma, a remuneração obtida por unidade de exposição ao risco (Sharpe et al., 1995). Assim, o Índice de Sharpe é dado por:

$$
S_{i}=\frac{R_{i}-R_{f}}{\sigma_{i}}
$$

Em que:

$R_{\mathrm{i}}=$ retorno médio no período analisado para o portfólio $i$;

$R_{f}=$ retorno do ativo livre de risco; e

$\sigma_{i}=$ desvio padrão dos retornos do portfólio $i$ no período sob análise.

\section{Índice $\mathbf{M}^{2}$ de Franco Modigliani e Leah Modigliani} Segundo Securato (1998), o Índice de Franco Modigliani e Leah Modigliani, também chamado Índice $\mathrm{M}^{2}$ é obtido por meio da construção de uma carteira formada pelo portfólio em análise e o ativo livre de risco, em composições tais que esta nova carteira tenha o mesmo risco do mercado. Portanto, o Índice $\mathrm{M}^{2}$ tem como objetivo mensurar o excesso de retorno do fundo em relação ao retorno de mercado se ambos tivessem a mesma volatilidade; ou seja, procura mostrar o quanto o fundo ganha, ou perde, em relação ao mercado, quando os riscos são equivalentes.

De acordo com Securato (1998), o índice $\mathrm{M}^{2}$ é dado pela seguinte equação:

$$
M^{2}=\sigma_{m} / \sigma_{i}\left(R_{i}-R_{f}\right)-\left(R_{m}-R_{f}\right)
$$

Em que:

$\sigma_{m}=$ desvio padrão dos retornos do mercado no período sob análise;

$\sigma_{i}=$ desvio padrão dos retornos do portfólio $i$ no período sob análise;

$R_{m}=$ retorno de mercado;

$R_{i}=$ retorno médio do portfólio $i$ no período analisado; $e$

$R_{f}=$ retorno do ativo livre de risco.

Tomando por base o Índice de Sharpe, o Índice $\mathrm{M}^{2}$ pode ser escrito da seguinte forma:

$$
M^{2}=\sigma_{m} \cdot I S-\left(R_{m}-R_{f}\right)
$$

Em que:

$$
\text { IS = Índice de Sharpe }
$$

Uma vez apresentados esses índices, vejamos a seguir os dados utilizados nesta pesquisa e os resultados obtidos.

\section{METODOLOGIA}

\section{Dados e amostra}

Os dados relativos aos investimentos de cada entidade foram obtidos por meio dos demonstrativos trimestrais Demonstrativos Analíticos de Investimento e Enquadramento das Aplicações (DAIEA) - fornecidos pelas entidades. Esses demonstrativos contêm os dados discriminados referentes à quantidade e valor de mercado de cada um dos títulos que compõem a carteira de investimento dos fundos de pensão aqui considerados. Apenas os investimentos no mercado à vista foram utilizados neste estudo.

Como proxy para o retorno do ativo livre de risco e para o retorno da carteira de mercado, foram utilizados o Certificado de Depósito Interfinanceiro (CDI) e o Ibovespa, respectivamente. Vale realçar aqui que, apesar de a poupança apresentar variância menor comparativamente ao CDI, é este o ativo que compõe a carteira dos fundos de pensão analisados, quando se trata de investimentos em renda fixa. Daí a razão de se optar pelo CDI como ativo livre de risco.

Devido à dificuldade de acesso aos dados das entidades de médio e pequeno porte, optou-se por uma amos- 
tra por acessibilidade, embora mantendo critérios de representatividade estatística, uma vez que essas entidades respondiam, quando da coleta, por $46,4 \%$ do total de ativos dos fundos de pensão existentes no Brasil.

A amostra foi formada por 11 entidades fechadas de previdência complementar, compreendendo fundos de grande e médio porte. Dentre estes, 9 eram patrocinados por empresas públicas e 2 por empresas privadas. Dos 10 maiores fundos de pensão do Brasil, 6 fizeram parte desta amostra. O período analisado foi de janeiro de 1999 a março de 2001, só não sendo maior devido à indisponibilidade dos dados dessas entidades.

Tendo como base o ativo total das entidades no início do período estudado, dividiu-se a amostra em três grupos. A Tabela 1 mostra tais grupos, assim como a caracterização das entidades quanto ao número de patrocinadores, de participantes e quanto ao volume médio de ações na carteira. A Tabela 2 mostra a composição da carteira de investimentos das entidades pertencentes à amostra no período considerado.

\section{Tratamento dos dados}

Em primeiro lugar, foi calculado o retorno de cada ação e, posteriormente, o retorno da carteira por meio da média ponderada dos retornos dos ativos individuais que a compõem. Em seguida, foi mensurado, conforme o modelo de mercado, o risco sistemático mensal; ou seja, o coeficiente beta, de cada ação das carteiras dos fundos de pensão no período analisado. Feito isto, calculou-se o risco sistemático de cada carteira em cada mês por meio da média ponderada dos betas de cada ação da carteira. Já o risco não sistemático, representado pelo desvio padrão, foi mensurado a partir da metodologia de cálculo de risco de carteira, que considera a covariância entre os ativos. A partir do cálculo do risco da carteira de ações, foi então aplicado o Capital Asset Pricing Model (CAPM), com o objetivo de estimar o retorno mensal das carteiras dos fundos.

Para a análise do período total (de abril de 1999 a março de 2001) e dos dois subperíodos (de abril de 1999 a março de 2000 e de abril de 2000 a março de 2001), foi necessário utilizar um procedimento no qual as variáveis pudessem representar todo o período. Calculou-se então o retorno médio observado (real) das carteiras de ações do período total e dos subperíodos por meio de média aritmética simples.

Para o cálculo do retorno estimado de cada um dos três períodos propostos realizou-se a regressão linear simples do excesso de retorno mensal da carteira sobre o excesso de retorno mensal do índice de mercado, obtendo-se assim os respectivos betas. A partir dos betas calculados para o período total e para os dois subperíodos, foi possível estimar o retorno por meio do modelo CAPM. Além deste, mensurou-se o Índice de Sharpe e o Índice $\mathrm{M}^{2}$ para cada um dos períodos.

É importante destacar que o CDI dos períodos aqui considerados foi obtido por meio da média aritmética simples de suas rentabilidade mensais, não havendo uma diferença relevante entre a rentabilidade média obtida e as mensais observadas. Como os dados referentes aos retornos de mercado mensais, representados pelo Ibovespa, apresentaram grandes oscilações no período estudado, optou-se pela utilização da mediana, visto que essa medida é menos influenciada pelos valores extre-

Tabela 1 - Caracterização e segmentação da amostra de acordo com 0 ativo total.

\begin{tabular}{|c|c|c|c|c|c|}
\hline GRUPO & ATIVO TOTAL (EM R\$) & ENTIDADE & $\begin{array}{c}\text { NÚMERO DE } \\
\text { PATROCINADORES }\end{array}$ & $\begin{array}{l}\text { NÚMERO APROXIMADO } \\
\text { DE PARTICIPANTES }(*)\end{array}$ & $\begin{array}{l}\text { QUANTIDADE MÉDIA DE } \\
\text { AÇÕES NA CARTEIRA }\end{array}$ \\
\hline \multirow{3}{*}{1} & \multirow{3}{*}{ Superior a 8 bilhões } & $\mathrm{F}$ & 2 & 71.100 & 157 \\
\hline & & G & 28 & 90.000 & 110 \\
\hline & & $\mathrm{H}$ & 2 & 123.700 & 306 \\
\hline \multirow{4}{*}{2} & \multirow{4}{*}{ De 1,5 a 8 bilhões } & A & não disponível & 41.000 & 59 \\
\hline & & $\mathrm{E}$ & 2 & 21.000 & 48 \\
\hline & & J & 6 & 39.300 & 57 \\
\hline & & K & 27 & 45.000 & 56 \\
\hline \multirow{4}{*}{3} & \multirow{4}{*}{$\begin{array}{l}\text { De } 70 \text { milhões } \\
\text { a } 1,5 \text { bilhão }\end{array}$} & B & 2 & 740 & 46 \\
\hline & & C & 2 & 12.200 & 68 \\
\hline & & D & 2 & 1.300 & 51 \\
\hline & & I & 11 & 24.500 & 57 \\
\hline
\end{tabular}

Nota: $\left({ }^{*}\right)$ Foram considerados como participantes 0 total de ativos e assistidos. 
mos da amostra do que a média, refletindo melhor o retorno de mercado.

\section{RESULTADOS E DISCUSSÃo}

A análise dos resultados das regressões demonstrou que os testes estatísticos apresentaram, de modo geral, resultados significativos (veja Tabelas 3 e 4). Por sua vez, os modelos de regressão atenderam ao nível de significância de 10\%; a estatística Durbin-Watson demonstrou não existir autocorrelação de primeira ordem; os resíduos apresentaram distribuição normal, conforme indicou o teste Jarque-Bera; e os $\mathrm{R}^{2}$ ajustados encontrados ficaram, em sua maioria, em torno de $80 \%$.

As bruscas oscilações da Bolsa de valores não deixaram de influenciar as carteiras analisadas, em especial nos meses de novembro e dezembro de 1999, junho e dezembro de 2000, e janeiro de 2001. Nesses períodos, todas as carteiras apresentaram o mesmo comportamento anormal evidenciado no mercado, caracterizado por uma grande elevação nas taxas de rentabilidade observadas. Já em setembro de 2000, fevereiro e março de 2001, constatou-se queda nos retornos em todas as carteiras das entidades da amostra.

No entanto, nos meses em que o retorno de mercado foi negativo, algumas entidades alcançaram taxas positivas de rentabilidade. Como exemplo, podemos citar o mês de julho de 1999, quando o retorno de mercado foi de $-10,00 \%$ e as entidades $\mathrm{H}$ e $\mathrm{K}$ obtiveram retornos de $4,00 \%$ e $1,60 \%$ respectivamente.

A partir da análise da rentabilidade observada no período total, verificou-se que as entidades D e E apresentaram os piores desempenhos dentre as carteiras avaliadas, e as entidades A, H e K destacaram-se por possuírem carteiras com melhores desempenhos (veja Gráfico 1).

Comparando os subperíodos, constatou-se que o desempenho das carteiras das entidades fechadas de previ-

Tabela 2 - Composição das carteiras dos fundos da amostra.

\begin{tabular}{|c|c|c|c|c|c|c|}
\hline \multirow[b]{2}{*}{ ENTIDADE } & \multirow[b]{2}{*}{ PERIODO } & \multicolumn{5}{|c|}{ DISCRIMINAÇÃO DOS INVESTIMENTOS } \\
\hline & & $\begin{array}{c}\text { TÍTULOS } \\
\text { PÚBLICOS(\%) }\end{array}$ & $\begin{array}{l}\text { RENDA } \\
\text { FIXA (\%) }\end{array}$ & $\begin{array}{c}\text { RENDA } \\
\text { VARIÁVEL (\%) }\end{array}$ & $\begin{array}{l}\text { INVESTIMENTOS } \\
\text { IMOBILIÁRIOS (\%) }\end{array}$ & $\begin{array}{c}\text { OUTROS } \\
(\%)\end{array}$ \\
\hline \multirow{2}{*}{ A } & $1^{0}$ & 8 & 73 & 12 & 8 & 0 \\
\hline & $2^{0}$ & 11 & 71 & 13 & 6 & 0 \\
\hline \multirow{2}{*}{ B } & $1^{0}$ & 0 & 68 & 20 & 9 & 3 \\
\hline & $2^{0}$ & 0 & 76 & 13 & 8 & 3 \\
\hline \multirow{2}{*}{ C } & $1^{0}$ & 8 & 49 & 26 & 12 & 5 \\
\hline & $2^{0}$ & 14 & 50 & 24 & 8 & 4 \\
\hline \multirow{2}{*}{ D } & $1^{0}$ & 0 & 71 & 16 & 10 & 4 \\
\hline & $2^{0}$ & 0 & 69 & 15 & 8 & 7 \\
\hline \multirow{2}{*}{$\mathrm{E}$} & $1^{0}$ & 12 & 70 & 7 & 6 & 4 \\
\hline & $2^{0}$ & 15 & 67 & 9 & 6 & 4 \\
\hline \multirow{2}{*}{$F$} & $1^{0}$ & 1 & 25 & 39 & 23 & 12 \\
\hline & $2^{\circ}$ & 1 & 31 & 36 & 23 & 9 \\
\hline \multirow{2}{*}{$\mathrm{G}$} & $1^{0}$ & 3 & 37 & 32 & 16 & 12 \\
\hline & $2^{0}$ & 4 & 51 & 25 & 13 & 8 \\
\hline \multirow{2}{*}{$\mathrm{H}$} & $1^{0}$ & 0 & 22 & 57 & 7 & 14 \\
\hline & $2^{\circ}$ & 0 & 25 & 58 & 6 & 11 \\
\hline \multirow{2}{*}{ I } & $1^{0}$ & 1 & 69 & 12 & 14 & 5 \\
\hline & $2^{0}$ & 0 & 71 & 11 & 12 & 6 \\
\hline \multirow{2}{*}{$\mathrm{J}$} & $1^{0}$ & 32 & 13 & 23 & 32 & 0 \\
\hline & $2^{0}$ & 61 & 11 & 10 & 18 & 0 \\
\hline \multirow{2}{*}{ K } & $1^{0}$ & 16 & 48 & 22 & 11 & 3 \\
\hline & $2^{0}$ & 26 & 36 & 27 & 9 & 3 \\
\hline
\end{tabular}

Nota: Os percentuais não somam 100\%, devido ao arredondamento dos valores. 
dência privada foi consideravelmente superior no primeiro período de estudo, quando o retorno médio mensal foi de 3,91\%, apresentando-se positivo em todas as entidades. Tal rentabilidade reflete o bom desempenho da Bolsa de valores, cuja rentabilidade média foi de $4,70 \%$ durante o período.

Em contrapartida, o retorno médio mensal de 0,24\% no segundo período ficou em conformidade com a multiplicidade de taxas de rentabilidade negativas apresentadas pela Bolsa de valores no mesmo período. O Ibovespa apresentou um retorno médio de $-1,25 \%$. Verificou-se que, dentre as 11 entidades analisadas na amostra, apenas seis mostraram um retorno positivo (veja Gráfico 1).

A análise risco-retorno de cada segmento demonstrou que o retorno observado dos fundos possui uma relação direta com o seu porte. Desse modo, o retorno médio em cada um dos períodos foi maior no Grupo 1 (entidades F, G e H) e menor no Grupo 3 (entidades B, C, D e I).

Quanto ao risco, observou-se que os fundos menores (Grupo 3) apresentaram os maiores riscos em cada um

Tabela 3 - Resultados da regressão do período total (de abril de 1999 a março de 2001).

\begin{tabular}{|c|c|c|c|c|c|}
\hline ENTIDADE & CONSTANTE & RM-RF & $\overline{\mathrm{R}}^{2}$ & DURBIN-WATSON & JARQUE- BERA \\
\hline A & $\begin{array}{l}0,021116 \\
t=1,910433 \\
\text { Sig }=0,0692\end{array}$ & $\begin{array}{l}0,982564 \\
t=5,343659 \\
\text { Sig }=0,0000\end{array}$ & 0,545047 & 2,206188 & 0,632697 \\
\hline B & $\begin{array}{l}0,005521 \\
t=0,915970 \\
\text { Sig }=0,3696\end{array}$ & $\begin{array}{l}0,877947 \\
t=14,37266 \\
\text { Sig }=0,000\end{array}$ & 0,899376 & 2,746721 & 1,282944 \\
\hline C & $\begin{array}{l}0,001353 \\
t=0,206416 \\
\text { Sig }=0,8384\end{array}$ & $\begin{array}{l}0,924458 \\
t=13,91650 \\
\text { Sig }=0,0000\end{array}$ & 0,893355 & 2,373291 & 0,553572 \\
\hline D & $\begin{array}{l}-0,017296 \\
t=-2,508906 \\
\text { Sig }=0,0200\end{array}$ & $\begin{array}{l}0,695625 \\
t=9,957456 \\
\text { Sig }=0,0000\end{array}$ & 0,810154 & 1,490252 & 0,089026 \\
\hline$E$ & $\begin{array}{l}-0,019932 \\
t=-1,959314 \\
\text { Sig }=0,0629\end{array}$ & $\begin{array}{l}0,702830 \\
t=6,817690 \\
\text { Sig }=0,0000\end{array}$ & 0,664140 & 2,011009 & 0,794593 \\
\hline $\mathrm{F}$ & $\begin{array}{l}0,004457 \\
t=1,038677 \\
\text { Sig }=0,3102\end{array}$ & $\begin{array}{l}0,592373 \\
t=13,62337 \\
\text { Sig }=0,0000\end{array}$ & 0,889208 & 2,060491 & 1,481614 \\
\hline G & $\begin{array}{l}0,004474 \\
t=0,740781 \\
\text { Sig }=0,4667\end{array}$ & $\begin{array}{l}0,653902 \\
t=10,684888 \\
\text { Sig }=0,0000\end{array}$ & 0,831089 & 1,998692 & 2,240592 \\
\hline $\mathrm{H}$ & $\begin{array}{l}0,019346 \\
t=3,115375 \\
\text { Sig }=0,0050\end{array}$ & $\begin{array}{l}0,576578 \\
t=9,162289 \\
\text { Sig }=0,0000\end{array}$ & 0,782911 & 1,980347 & 0,904731 \\
\hline I & $\begin{array}{l}0,004719 \\
t=0,573008 \\
\text { Sig }=0,5724\end{array}$ & $\begin{array}{l}0,804189 \\
t=9,636158 \\
\text { Sig }=0,0000\end{array}$ & 0,799748 & 2,497094 & 0,044079 \\
\hline J & $\begin{array}{l}0,005348 \\
t=0,862849 \\
\text { Sig }=0,3975\end{array}$ & $\begin{array}{l}0,845909 \\
t=13,46795 \\
\text { Sig }=0,0000\end{array}$ & 0,886914 & 1,545374 & 3,226129 \\
\hline K & $\begin{array}{l}0,016035 \\
t=1,859549 \\
\text { Sig }=0,0764\end{array}$ & $\begin{array}{l}0,540349 \\
t=6,183585 \\
\text { Sig }=0,0000\end{array}$ & 0,618173 & 2,488580 & 0,049294 \\
\hline
\end{tabular}

Notas: $\mathrm{t}$ = estatística; Sig = significância 
HUDSON FERNANDES AMARAL · CAROLINE SALES ISSA VILAÇA · CAMILA FIGUEIREDO MARQUES BARBOSA · VALÉRIA GAMA FULLY BRESSAN

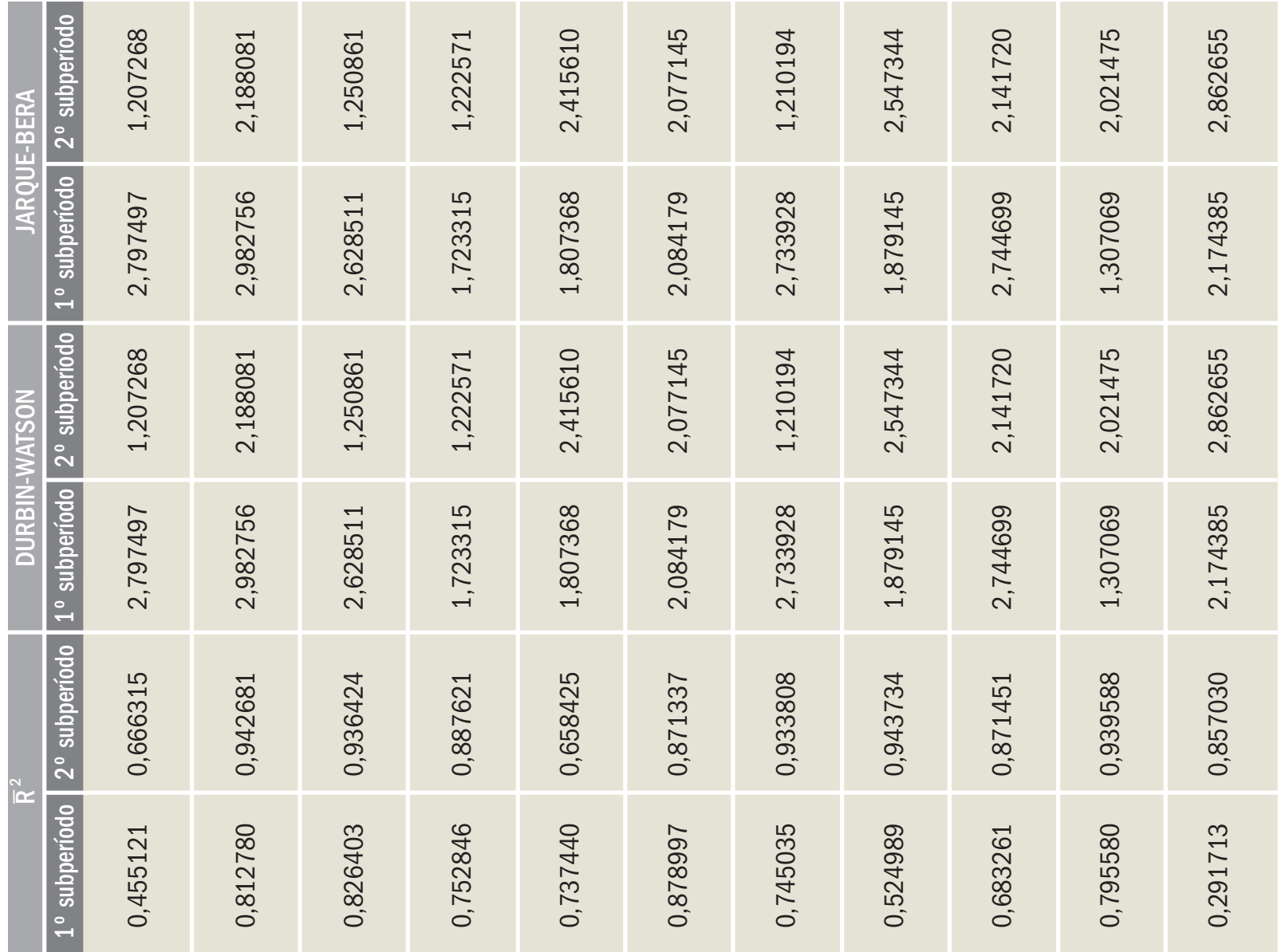

융

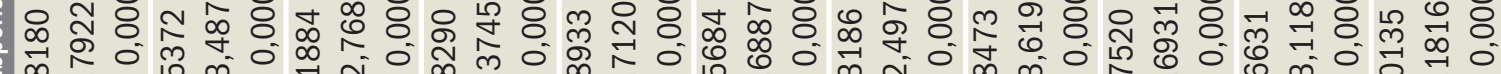
年 is "⿻

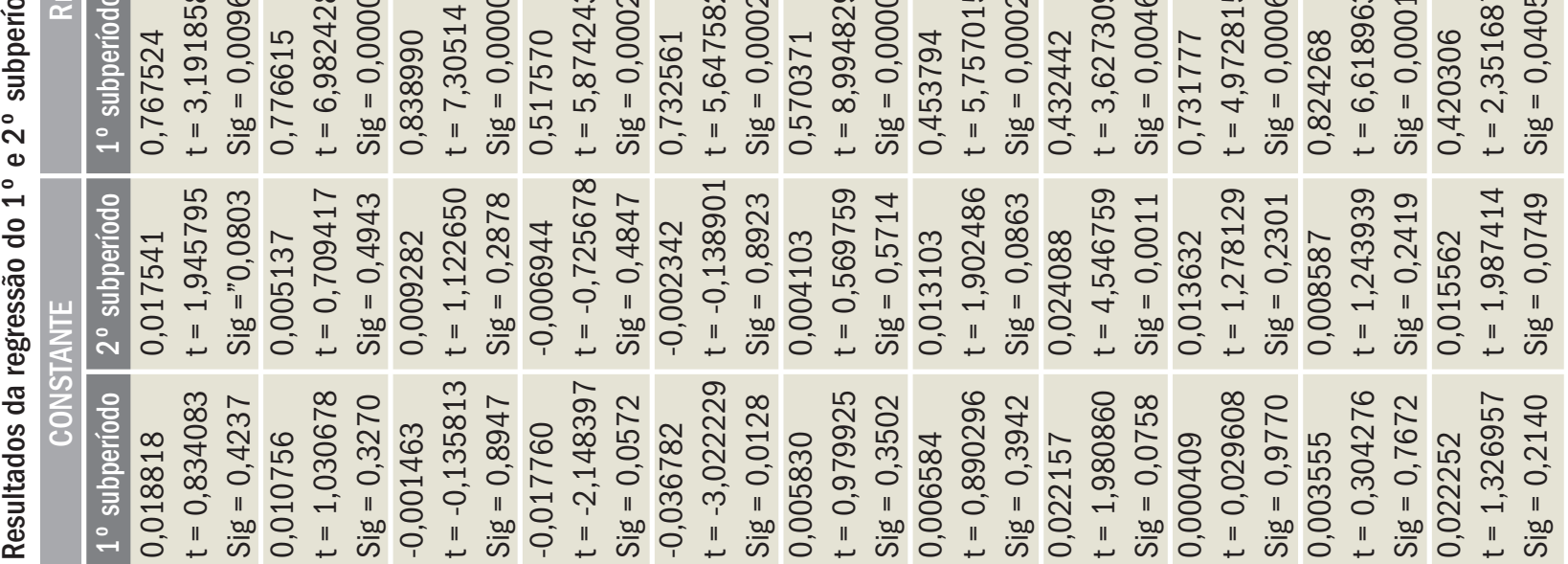
帝 
dos períodos. Já o Grupo 1 apresentou os menores riscos, com exceção do segundo período, quando o risco observado no Grupo 2 (entidades A, E, J e K) foi inferior (veja Tabela 5).

A relação risco-retorno das carteiras de ações das entidades, efetuada por meio da regressão da variável representativa do risco (beta) com o retorno observado de cada entidade, demonstrou uma relação inversa entre risco e retorno quando se analisa o período total e o segundo período. No entanto, apenas o segundo período atendeu ao nível de significância de 10\%. A análise do perío- do total e do primeiro período demonstra que os coeficientes beta não atenderam ao nível de significância (veja Tabela 5).

Os resultados demonstram que as entidades A, $\mathrm{He} \mathrm{K}$, além de possuírem os maiores retornos, são também as mais eficientes no gerenciamento de riscos, conseguindo uma combinação de maior retorno e menor risco, comparativamente aos outros fundos.

O contraste entre os retornos estimados e os retornos reais do período total permitiu inferir que as carteiras dos fundos de pensão tiveram um retorno satisfatório no

Gráfico 1 - Retorno real médio mensal das carteiras de ações dos fundos de pensão.

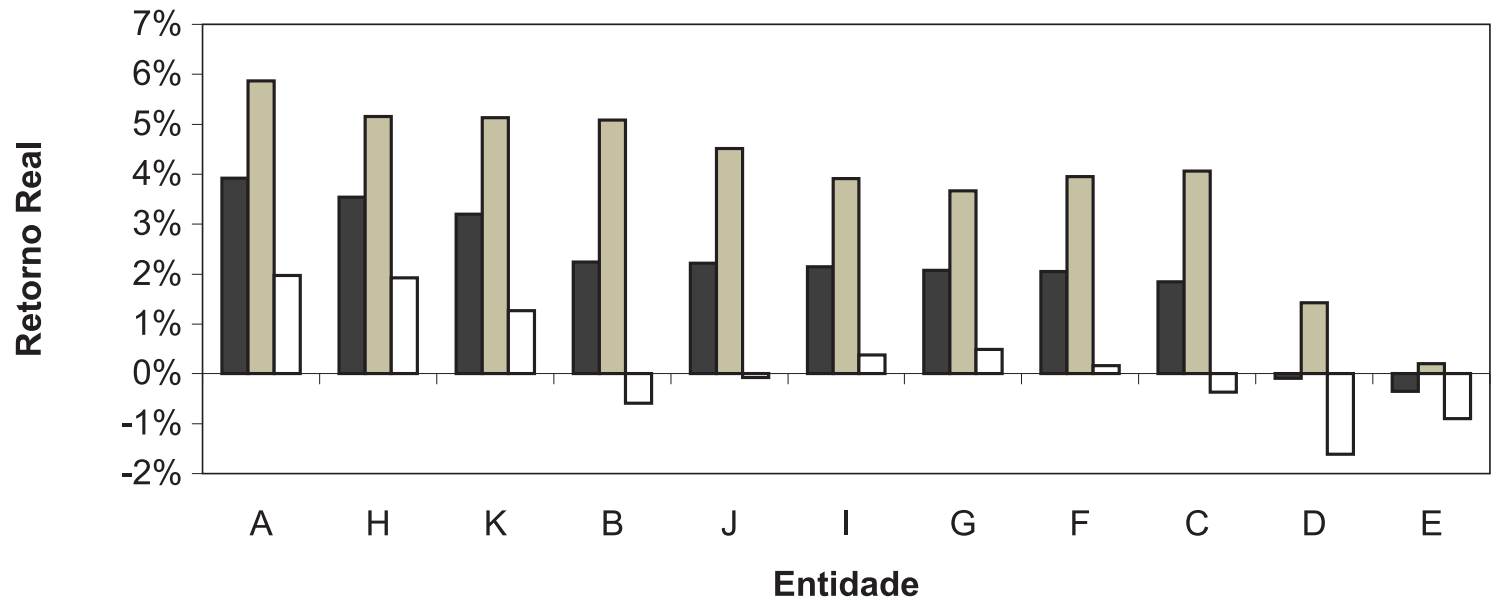

Período total $\square 1^{\circ}$ Sub-período $\square 2^{\circ}$ Sub-período

Tabela 5 - Risco, retorno e resultados estatísticos da regressão Beta x Retorno real.

\begin{tabular}{|c|c|c|c|c|c|}
\hline \multirow{2}{*}{ PERÍODO } & \multicolumn{3}{|c|}{ RISCO E RETORNO POR SEGMENTO } & \multicolumn{2}{|c|}{ BETA X RETORNO REAL } \\
\hline & SEGMENTO & RISCO (BETA) & RETORNO & COEFICIENTE DE DETERMINAÇÃO & SIGNIFICÂNCIA \\
\hline \multirow{3}{*}{ Período Total } & Grupo 1 & 0,61 & $2,56 \%$ & \multirow{3}{*}{$-3,125$} & \multirow{3}{*}{0,313} \\
\hline & Grupo 2 & 0,67 & $2,25 \%$ & & \\
\hline & Grupo 3 & 0,83 & $1,54 \%$ & & \\
\hline \multirow{3}{*}{$1^{\circ}$ Período } & Grupo 1 & 0,48 & $4,26 \%$ & \multirow{3}{*}{0,130} & \multirow{3}{*}{0,971} \\
\hline & Grupo 2 & 0,69 & $3,93 \%$ & & \\
\hline & Grupo 3 & 0,72 & $3,62 \%$ & & \\
\hline \multirow{3}{*}{$2^{\circ}$ Período } & Grupo 1 & 0,71 & $0,85 \%$ & \multirow{3}{*}{$-4,339$} & \multirow{3}{*}{0,022} \\
\hline & Grupo 2 & 0,67 & $0,57 \%$ & & \\
\hline & Grupo 3 & 0,94 & $-0,55 \%$ & & \\
\hline
\end{tabular}


que diz respeito a seus investimentos em ações. Com exceção das carteiras das entidades D e E, todas apresentaram taxas de rentabilidade positivas e superiores às esperadas; ou seja, as carteiras de ações das entidades fechadas de previdência privada obtiveram um retorno superior ao que seria justo em decorrência do risco por elas incorrido.

Os resultados encontrados a partir do Índice de Sharpe para o período total de análise indicaram que, com exceção das entidades D e E, todas apresentaram remuneração pelo risco superior ao do mercado, destacando-se mais uma vez as entidades A, H e K. O Índice de Sharpe alcançado por estas foi bastante superior ao do mercado, que se apresentou negativo no período total. O mesmo resultado foi encontrado por meio do Índice $\mathrm{M}^{2}$. Apenas nas entidades D e E este índice apresentou-se negativo. Ou seja, se a volatilidade das carteiras em análise fosse equivalente à do mercado, apenas as entidades D e E não teriam tido rentabilidade superior ao Ibovespa.

A diferença das rentabilidades observadas nos dois períodos deve ser analisada concomitantemente à discrepante diferença nos retornos estimados nesses períodos; ou seja, tanto os retornos observados quanto os estimados, estes mais do que aqueles, foram significativamente inferiores no segundo período. No primeiro período, apesar de todas as entidades terem obtido rentabilidade média positiva, as carteiras das entidades C, D, E e I não atingiram a taxa de retorno esperada. Em contrapartida, apesar das várias taxas de rentabilidade negativas durante o segundo período de estudo, todas as entidades tiveram retorno observado superior ao esperado.

$\mathrm{O}$ fato de o retorno estimado ter sido muito menor no segundo período pode ser explicado a partir da análise do desempenho do Ibovespa e do CDI durante o período de estudo. A taxa de retorno do mercado (obtida pela mediana) foi de $4,98 \%$ no primeiro período e de $-5,20 \%$ no segundo. Por sua vez, o retorno livre de risco (obtido pela média aritmética simples) foi de $1,60 \%$ e $1,27 \%$ no primeiro e segundo períodos, respectivamente. No entanto, apesar de ambas as taxas apresentarem queda no desempenho durante o segundo período, é a diferença entre elas; ou seja, o excesso de retorno de mercado, que é relevante, uma vez que é esse indicador que afeta diretamente o retorno esperado. Assim, a discrepância do prêmio pelo risco de mercado entre os períodos, $3,38 \%$ no primeiro e $-6,47 \%$ no segundo, resultou em uma grande queda dos retornos esperados das carteiras das entidades no segundo período, garantindo a elas um superávit entre o retorno real e o estimado das suas carteiras de ações.
Os resultados do Índice de Sharpe para o primeiro período indicaram que, mais uma vez, as entidades D e E tiveram índices negativos e inferiores aos do mercado. Além dessas, também as entidades $C$, I e J não conseguiram remuneração pelo risco superior à do mercado. O Índice $\mathrm{M}^{2}$, por sua vez, foi negativo para as entidades C, D, E, I e J, indicando que essas carteiras não se mostraram vantajosas em relação ao mercado nesse período. Entretanto, deve-se considerar que os índices das entidades C, I e J foram - $0,69 \%,-0,71 \%$ e $-0,19 \%$, respectivamente, indicando que elas não apresentam um desempenho tão inferior em relação ao mercado quanto as entidades $\mathrm{D}$ e $\mathrm{E}$, cujos índices foram $-3,68 \%$ e $-5,05 \%$.

O cálculo do Índice de Sharpe para o segundo período indicou que, com exceção das carteiras das entidades A e H, todas apresentaram índices negativos. Porém, comparativamente ao mercado, todas as entidades obtiveram desempenho superior. Os resultados obtidos com o Índice $\mathrm{M}^{2}$ confirmam tal situação, pois esse foi positivo para todos os fundos.

Diante do exposto, verifica-se que os indicadores de desempenho utilizados, CAPM, Índice de Sharpe e Índice $\mathrm{M}^{2}$, apresentaram resultados muito semelhantes entre si, confirmando a tendência de rentabilidade apontada para essas carteiras.

\section{CONCLUSÃO}

Os fundos de pensão podem atuar como agentes do desenvolvimento econômico ao investirem seus recursos de forma produtiva. Neste trabalho, foi considerada como investimento produtivo a aplicação de recursos nas empresas, seja por meio do mercado primário, seja por meio do mercado secundário. Acredita-se que a compra de títulos no mercado secundário incentive os negócios em Bolsas de valores, estimulando a emissão de novas ações e até mesmo a abertura de capital e promovendo o desenvolvimento econômico.

O Capital Asset Pricing Model (CAPM) e os índices de Sharpe e $\mathrm{M}^{2}$ foram utilizados para avaliar o desempenho das carteiras de investimento em ações dos fundos de pensão, verificando, assim, a relação risco-retorno desses fundos e o papel que desempenham na formação de poupança interna e na aplicação de recursos no setor produtivo. A mensuração e a análise do desempenho das carteiras das entidades permitiram concluir que, no geral, os retornos reais superaram os retornos estimados e os fundos de pensão conseguiram remuneração pelo ris- 
co superior ao do mercado. No entanto, os resultados indicaram que há uma diferença nesse desempenho quando se segmentam os fundos por porte. Os maiores fundos apresentaram as maiores taxas de retorno e, no geral, os menores riscos.

Vale ressaltar que, embora os resultados apresentados estejam, a princípio, limitados ao período compreendido entre 1999 e 2001, a extensão das conclusões obtidas com o CAPM, os índices Sharpe e $\mathrm{M}^{2}$ são aplicáveis ao biênio 2002/2003. Isso porque a composição das carteiras dos fundos de pensão apresentou constituição similar às carteiras analisadas no período estudado.

Uma vez que o fim último dos fundos de pensão consiste em garantir a concessão de benefícios aos seus participantes, o que implica empregar os recursos nas modalidades mais rentáveis, sempre considerando o risco, pode-se dizer que o fato de os investimentos em ações possibilitarem retornos superiores aos esperados estimularia a sua priorização pelas entidades, o que geraria, por um lado, maior valor agregado ao fundo e, por outro, um incremento da poupança interna do país, respaldado pela aplicação eficiente dos recursos; ou seja, pelo investimento no setor produtivo.

Entretanto, devem ser tomadas algumas medidas para que os fundos de pensão desempenhem um papel mais relevante no financiamento do crescimento econômico brasileiro. Um incentivo ao incremento da participação da população nesses fundos seria importante na medida em que aumentaria o nível de poupança interna a partir da disponibilização de maiores recursos para o aumento da capacidade produtiva. Além disso, a contribuição dos fundos para o crescimento econômico depende de políticas públicas adequadas. Tendo em vista que os requisitos e as regras para os investimentos dos fundos, fixados pelos órgãos de supervisão, aparecem como um dos principais condicionantes da distribuição das carteiras de ativos de fundos de pensão, os responsáveis pela elaboração da legislação pertinente aos limites de aplicações das entidades fechadas de previdência privada devem se empenhar para que esta possibilite a otimização da alocação dos recursos.

Deve-se considerar a possibilidade de a ação estatal restringir-se à fiscalização e ao controle da saúde financeira das entidades, uma vez que os limites de investimentos em renda variável impedem a otimização da alocação de recursos no que diz respeito aos investimentos no setor produtivo. As restrições deveriam ser eliminadas, dando-se liberdade para que os administradores dos fundos de pensão definam as políticas de investimentos dos fluxos de receitas e dos recursos acumulados, o que permitiria uma maior aplicação dos recursos em renda variável, implicando em um incremento do investimento produtivo.

Os fundos de pensão podem desempenhar importante papel na formação de poupança interna e no desenvolvimento da economia na medida em que canalizem seus recursos para o setor produtivo. Visto que a ampliação desses investimentos está intimamente relacionada às políticas e ações governamentais, é imprescindível que estas atuem de forma a proporcionar um incremento da participação desses fundos no financiamento do crescimento econômico brasileiro.

\section{REFERÊNCIAS BIBLIOGRÁFICAS}

BAIMA, F. R. Análise de desempenho dos investimentos dos fundos de pensão no Brasil. 1998. Dissertação (Mestrado) - Programa de pós-graduação em Engenharia de Produção da Universidade Federal de Santa Catarina, Santa Catarina, 1998.

BODIE, Z.; KANE A.; MARCUS, A. Investments. New York: McGraw-Hill, 1996

CASTRO, H. O. P.; OliVEIRA, L. G. S.; CARDOSO, R. F; WERLANG, S. R. C.; MAGALHÃES, U. Regimes complementares de previdência. Rio de Janeiro: FGV/EPGE, 1994. 48 p. (Ensaios Econômicos, 238).

CINTRA, M. A. M. Frágil argumento. Jornal da Unicamp, v. XIV, n. 149, 2000. p. 8. Disponível em: <http://www.unicamp.br/unicamp/ unicamp_hoje/ju/fev2000/pagina8-Jul49.html>. Acesso em: 15 jun. 2002.

FIABV - FEDERACIÓN IBEROAMERICANA DE BOLSAS DE VALORES. Poupança privada e desenvolvimento econômico: mecanismos de estímulo e papel das bolsas de valores. Buenos Aires, 2002. 66 p. Disponível em:<http://www.fiabv.org/fiabv/archivos/pdf/Poupanca-privada.PDF>. Acesso em: 20 maio 2002

FRANÇA, R. C. A influência dos fundos de pensão para o crescimento econômico brasileiro. 2002. 120 p. Dissertação (Mestrado em Administração) Faculdade de Ciências Econômicas da Universidade Federal de Minas Gerais, Belo Horizonte, 2002.

GITMAN, L. Princípios de administração financeira. 7. ed. São Paulo: Harbra, 1997. 841 p.

INFORMAÇÕES MACROECONÔMICAS. Disponível em: <http:// www.abrapp.org.br/estatisticas/internacional/estatística_regional/ estatisticas_regionais.htm>. Acesso em: 11 set. 2002.

INTERNATIONAL FINANCE CORPORATION (IFC). Investment funds in emerging markets. Washington: World Bank, 1996, apud FEDERACIÓN IBEROAMERICANA DE BOLSAS DE VALORES (FIABV). Poupança privada e desenvolvimento econômico: mecanismos de estímulo e papel das Bolsas de valores, Buenos Aires, 2002. 66 p. Disponível em: <http:// www.fiabv.org/fiabv/archivos/pdf/Poupanca-privada.PDF>. Acesso em: 20 maio 2002 
MATIJASCIC, M. Fundos de pensão e rearticulação da economia brasileira. Campinas: UNICAMP, 1994. 49 p. (Texto para discussão, 40).

MIRANDA, R. B.; RODRIGUES Jr., W.; SILVA, M. M. Intermediação de poupança para investimento no setor produtivo. Brasília: IPEA, 1998. 32 p. (Texto para discussão, 597).

MCKINNON, R. I. Money and capital in economic development. Washington, D.C.: Brookings Institution, 1973, apud STUDART, R. Pension funds and the financing of productive investments: an analysis based on Brazil's recent experience. Santiago, 2000. 63 p. Disponível em: <http:// www.ancepp.org.br/biblioteca/cepal/eventocepalppt.htm>. Acesso em: 08 de jan. 2002

MODIGLIANI, F; MODIGLIANI, L. Risk-adjusted performance. The Journal of Portfolio Management, v. 23, n. 2, p. 45-54, 1997

MOTTA, J. R. S. T. Uma análise da relação entre mercado de capitais e desenvolvimento. Brasília: Consultoria Legislativa, 2001. 6 p. Disponível em: <http://www.camara.gov.br/internet/diretoria/conleg/estudos/ 011858.pdf.>. Acesso em 03 jul. 2002.

PEREIRA, F; MIRANDA, R. B.; SILVA, M. M. Os fundos de pensão como geradores de poupança interna. Brasília: IPEA, 1997. 56 p. (Texto para discussão, 480).
SECURATO, J. R. Índice $M^{2}$ de F. Modigliani e L. Modigliani para avaliação da performance de fundos: o índice de MM - Modigliani Modificado. In: III SEMEAD, 1998, São Paulo: FEA-USP, 1998.

SHARPE, W. F. Capital asset prices: a theory of market equilibrium under conditions of risk. Journal of Finance, v. 19, n. 3, p. 425-442, 1964.

SHARPE, W. F; ALEXANDER, G. J.; BAILEY, J. V. Investments. $5^{a}$ ed. New Jersey: Prentice Hall, 1995, p. 261-292.

SHAW, E. S. Financial deepening in economic development. New York: Oxford University Press, 1973, apud STUDART, R. Pension funds and the financing of productive investments: an analysis based on Brazil's recent experience. Santiago, 2000. 63 p. Disponível em: <http:// www.ancepp.org.br/biblioteca/cepal/eventocepalppt.htm>. Acesso em: 08 jan. 2002.

STUDART, R. Pension funds and the financing of productive investments: an analysis based on Brazil's recent experience. Santiago, 2000. 63 p. Disponivel em: <http://www.ancepp.org.br/biblioteca/cepaleventocepalppt. htm>. Acesso em: 08 jan. 2002.

Artigo recebido em 31.01.2003. Aprovado em 12.08.2003.

\section{Hudson Fernandes Amaral}

Professor do CEPEAD/CAD/UFMG e Coordenador do NUFI/UFMG. Doutor em Administração pela Université Pierre Mendès France, Grenoble II, França. Interesses de pesquisa em finanças.

E-mail: hfamaral@face.ufmg.br

Endereço: Rua Curitiba, 832/1002 - Centro - Belo Horizonte - MG, 30170-120.

\section{Caroline Sales Issa Vilaça}

Graduanda em Administração de Empresas pela UFMG. Pesquisadora do NUFI/CEPEAD/CAD/UFMG e bolsista do CNPq. Interesses de pesquisa em finanças.

E-mail: cvilaca@cepead.face.ufmg.br

Endereço: Rua Jornalista Jair Silva, 278/301 - Cruzeiro - Belo Horizonte - MG, 30310-290.

\section{Camila Figueirêdo Marques Barbosa}

Graduanda em Administração de Empresas pela UFMG. Pesquisadora do NUFI/CEPEAD/CAD/UFMG e bolsista do CNPq. Interesses de pesquisa em finanças.

E-mail: cbarbosa@cepead.face.ufmg.br

Endereço: Rua Curitiba, 832/1002 - Centro - Belo Horizonte - MG, 30170-120.

Valéria Gama Fully Bressan

Professora Substituta do CEPEAD/CAD/UFMG. Mestre em Economia Aplicada pela UFV. Interesses de pesquisa em finanças e cooperativismo.

E-mail: valeriabressan@yahoo.com.br

Endereço: Rua Curitiba, 832/1002 - Centro - Belo Horizonte - MG, 30170-120. 